\title{
Occupational Exposure of Train Drivers to Static and Extremely Low Frequency Magnetic Fields in Tehran Subway
}

\author{
Hamed Jalilian, ${ }^{1}$ Kamran Najafi, ${ }^{2}$ Mohammad Reza Monazzam,,${ }^{3,}$ Yahya Khosravi, ${ }^{4}$ and Jamshid \\ Jamali $i^{5,6}$ \\ ${ }^{1}$ Student Research Committee, Shiraz University of Medical Sciences, Shiraz, IR Iran \\ ${ }^{2}$ Department of Occupational Health Engineering, Tehran University of Medical Sciences, Tehran, IR Iran \\ ${ }^{3}$ Department of Occupational Health Engineering, School of Health, Tehran University of Medical Sciences, Tehran, IR Iran \\ ${ }^{4}$ Research Center for Health, Safety and Environment, Alborz University of Medical Sciences, Karaj, IR Iran \\ ${ }^{5}$ Social Determinants of Health Research Center, Mashhad University of Medical Sciences, Mashhad, IR Iran \\ ${ }^{6}$ Department of Biostatistics and Epidemiology, School of Health, Mashhad University of Medical Sciences, Mashhad, IR Iran \\ "Corresponding author: Mohammad Reza Monazzam, Department of Occupational Health Engineering, School of Health, Tehran University of Medical Sciences, Tehran, IR, IR \\ Iran. Tel: +98-2188992663, Fax: +98-2188992663, E-mail: mmonazzam@hotmail.com
}

Received 2017 April 08; Revised 2017 May 30; Accepted 2017 July 11.

\begin{abstract}
Background: Electrification of transport systems currently deserves top priority in Iran. Such systems generate a magnetic field in static or extremely low frequency ranges. Therefore, train drivers may be exposed to these fields occupationally.

Objectives: The current study aimed to measure the intensity of static magnetic field (SMF) and extremely low frequency magnetic fields (ELF-MF) in the subway trains of Tehran City in different train types and situations to show drivers' exposure to SMF and ELF-MF. Methods: Two AC and DC trains were randomly selected from lines 1 and 2, one AC train from line 4, and two ACi trains from line 5. The SMF and ELF-MF levels were measured based on BS EN 50500:2008 and recommendations in other studies using TES-1394 (ELFMF meter) and HI-3550 (SMF meter). Ceiling values of ELF-MF and SMF were used for assessment of train driver's exposure. One-way ANOVA, with Tukey post hoc test, and independent sample T-test were used for data analysis.

Results: Maximum SMF and ELF-MF exposures were $0.52 \mathrm{mT}$ (at DC trains- in trip situation) and $7.90 \mu \mathrm{T}$ (at ACi trains- in trip situation), respectively, and the minimum exposures to SMF and ELF-MF were measured among the drivers of ACi $(<0.1 \mathrm{mT}$ - in all situations) and AC trains ( $0.08 \mu \mathrm{T}$ - in acceleration situation), respectively.

Conclusions: As the obtained results suggest, in none of the situations, exposure of train drivers to ELF-MF and SMF exceeded the threshold limits recommended by ACGIH. However, the effects of these fields should not be ignored because different studies have reported adverse health consequences of these fields.
\end{abstract}

Keywords: Magnetic Field, Occupational Exposure, Train Driver, Subway

\section{Background}

Electrification of transport systems currently deserves top priority in Iran. Regardless of the fact that all types of vehicles are exposed to external electromagnetic fields (1-3), electric transportation systems, due to their design and the use of electric fuel, can generate an additional significant magnetic fields (MF). In urban rail transit system, propulsion motors are electrical, of alternating current (AC) or direct current (DC) types. Accordingly, the power supply could also be AC or DC (4). Such systems generate static magnetic field (SMF) and extremely low frequency magnetic fields (ELF-MF). Steady electric or magnetic fields are called 'static' that means they do not fluctuate over time (5). Extremely low frequency is in the range of 3 to 300 $\mathrm{Hz}$ (6). A number of studies have warned about the health effects of exposure to MF in rail transit. The most commonly reported of which include a 3-fold increased risk for chronic lymphocytic leukemia in engine drivers (7), double incidence rate of chronic and acute lymphocytic leukemia in engine drivers and conductors compared to the average Swedish male population (8), altering the urinary 6-hydroxymelatonin sulfate excretion (9), increased risk of sudden cardiac death (10), and cardiovascular mortality (11). Exposure to MF induced by electrified public transport has been the center of concern in different countries such as Malaysia (12), Russia (13,14), Italy (15), and Australia (4).

Halgamuge et al. measured the electromagnetic fields emitted by trams, trains, and hybrid cars in Australia. The average of minimum and maximum MF was measured at various locations inside the vehicles. According to their results, minimum ELF-MF values were 0.6, 0.01, 1.5, 0.5, and $0.3 \mathrm{mG}$ measured at rear floor, middle floor, front floor, driver side seat, and above the train drivers' cabin, respec- 
tively, while maximum values in these places were 3.60, 8.70, 8.30, 4.70, and 5.50 $\mathrm{mG}$, respectively (4).

In the study of Dietrich and Jacobs (16), ELF-MF was measured in different types of electric vehicles. They reported average ELF-MF of $6 \mathrm{mG}$ in electric car and light trunk, $14 \mathrm{mG}$ in jetliner and shuttle tram (AC Electric), 20 $\mathrm{mG}$ in electric shuttle bus, and $49 \mathrm{mG}$ in commuter train (AC Electric). In a research on Italian railway industry, maximum SMF and ELF-MF values were measured at the driver's cabin of either AC or DC trains. They categorized the AC trains to A and B and DC trains to D and E. Based on their results, in the DC system, alternating and static magnetic fields were 20 and $80 \mu \mathrm{T}$ in train A and 4 and $160 \mu \mathrm{T}$ in train $\mathrm{B}$, respectively, while in the AC system, alternating and static magnetic fields were 9.31 and $100 \mu \mathrm{T}$ in train $\mathrm{E}$ and 5.46 and $120 \mu \mathrm{T}$ in train $\mathrm{F}$, respectively (15).

After about 20 years of establishment of Tehran subway, no occupational assessment has been conducted on drivers' exposure to ELF-MF and SMF. In addition, over the world, limited studies have assessed ELF-MF and SMF in different train types and situations. This study indicates the details of drivers' exposure to MF. Therefore, the current study aims to measure the intensity of SMF and ELF-MF in the subway trains of Tehran city in different train types and situations and shows drivers' exposure to SMF and ELF-MF.

\section{Methods}

\subsection{Study Area}

The study area was the Tehran subway. In order to measure MFs, in the first step, the basic data on train types, railway stations, train arrivals and departures, places of railroad switch, and work shifts of train drivers were gathered from Tehran urban and suburban subway operation company (TUSROC). According to the TUSROC and field visits, the subway system consists of 5 lines among which, line 5 extends outside of the city and joins the subway line of the next city, Karaj. The power supply of lines 1, 2, and 4 is a third rail while line 5 operates with overhead power supply. There are three types of trains in the sub-way system, including $\mathrm{AC}$ and DC in-city trains and AC intercity trains. Either AC or DC trains are travelling at the all railway lines, except for line 4, which offers transport services only with trains of AC type. Power supply of AC trains is $750 \mathrm{~V} \mathrm{DC}$ nominal current. An inverter transforms $750 \mathrm{~V}$ DC power into $380 \mathrm{VAC}(30-300 \mathrm{~Hz})$ for the engine of the trains.

In DC trains, electricity is supplied from a third rail carrying a nominal 750 V DC current and directly used for motor traction. In intercity AC (ACi) trains, electricity is supplied from $25 \mathrm{kV}(50 \mathrm{~Hz})$ overhead lines. In this research, 3 $\mathrm{AC}$ (from lines 1, 2, and 4), 2 DC (from lines 1 and 2), and $2 \mathrm{ACi}$ trains (from line 5) were randomly selected and the trains ID was recorded.

\subsection{Instruments}

In the current study, a TES-1394 (Electrical Electronic Corp) with frequency range of $30-2000 \mathrm{~Hz}$ was used to measure ELF-MF. This instrument is a triaxial device ELF-MF meter, with sampling time of less than $1 \mathrm{~s}$. The TES-1394 is useful for measuring magnetic fields up to $200 \mu \mathrm{T}$ with a measurement accuracy of $\pm 5 \%$. The HI-3550 Magnetic Field Monitor (Holaday Industries, Inc.) was also used to measure SMF. The measurement range of HI-3550 was 0.1 to $300 \mathrm{mT}$ with a measurement accuracy of $\pm 10 \%$. The sampling time of HI-3550 was 3 seconds.

Atomic energy organization of Iran, non-ionizing radiation part, calibrated both devices and reported no correlation factor for the devices.

\subsection{Measurement Procedures}

The SMF and ELF-MF levels were measured for each train (including $3 \mathrm{AC}, 2 \mathrm{DC}$, and $2 \mathrm{ACi}$ trains) in forward/return trips during peak/none-peak hours. The measurements were done when the trains were in trip, between stations (3 stations), during breaking or deceleration (3 breakings), during traction or acceleration (3 tractions), and during railroad switching (2 for each forward and return trip). Based on the BS EN 50500:2008 recommendations, the measurement of railway environment magnetic fields levels with respect to human exposure in a cabin shall be carried out close to the sources of emission of the trains where workers usually can be in normal operating conditions of train and appliance at the driver seat. The horizontal measuring distance to the walls and appliance was $0.3 \mathrm{~m}$, at least (17). Therefore, all measurements were done at the height of about $1 \mathrm{~m}$ from the cabin floor, in the nearest point to the driver. For better results, measurements were carried out with three replications in 3-second intervals. The minimum, maximum, and average values were recorded for each measurement time. The mean SMF and ELF-MF values were taken for the compartments of the trains.

\subsection{Exposure Assessment}

Generally, about 1200 drivers worked five days a week in 3 different shifts (from 5 a.m. to 11 p.m.). Normally, shifts' length was 8 hours, but they did not work full time in a shift, and there were two 30-minute breaks. Usually, the driver in the master cabin derived and controlled by the train. Drivers were spending about $90 \%$ of their working time in each shift in there (about 7 hours). 
ACGIH has established threshold limit values (TLV) for occupational exposure to SMF and ELF-MF. According to the threshold TLVs for SMF (Whole body ceiling exposure limit: 2 T) and ELF-MF(Whole body ceiling exposure limit in $60 \mathrm{~Hz}$ for ACGIH: $1 \mathrm{mT}$ ), occupational exposure assessment should be based on the maximum exposure value (ceiling value) (6).

\subsection{Data Analysis}

Data analyses were conducted using SPSS Ver. 14 software. An analysis of variance (one-way ANOVA) with Tukey post hoc test was used for comparison of ELF-MF and SMF values in $\mathrm{AC}, \mathrm{DC}$, and $\mathrm{ACi}$ trains. In addition, this test was applied to compare ELF-MF values in various types of trains in different situations. Moreover, an independent sample T-test was used for comparison of SMF values in various types of trains in different situations.

\section{Results}

Table 1 shows minimum, maximum, mean, and standard deviation (SD) of ELF-MF and SMF in driver's cabin at different situations of acceleration (traction), in-trip (with almost constant-speed motion), deceleration (at braking times), and rail switch.

Maximum SMF was $0.5 \mathrm{mT}$ measured in DC trains while the minimum SMF of $<0.1 \mathrm{mT}$ was found in ACi trains. Maximum and minimum ELF-MF values were $7.90 \mu \mathrm{T}$ and 1.87 $\mu \mathrm{T}$ measured in ACi and DC trains, respectively.

According to the results, maximum and mean values of ELF-MF in ACi trains (the highest amount) were respectively 7.90 and $2.53 \mu \mathrm{T}$ measured in trip situation. However, in DC trains, maximum and mean ELF-MF values (the highest amount) were respectively 1.87 and $0.46 \mu \mathrm{T}$ measured at the time of acceleration. Furthermore, maximum and mean SMF values (the highest amount) in AC trains were respectively 0.35 and $0.14 \mathrm{mT}$ measured during acceleration; while in DC trains, the values were 0.52 and $0.12 \mu \mathrm{T}$ measured respectively in trip and at the time of acceleration.

Table 2 compares maximum SMF and ELF-MF values in AC, DC, and ACi trains during acceleration, in-trip, deceleration, and rail switch situations.

As observed in the Table 2, there is a significant difference between the ELF-MF values of AC trains in trip and rail switch modes $(\mathrm{P}=0.004)$. In DC trains, ELF-MF shows a significant difference in none of the measurement situations. There was also a significant difference between ELF-MF values of ACi trains during acceleration and deceleration ( $P$ $=0.002)$ as well as in rail switch $(\mathrm{P}=0.003)$. The results also confirm a significant difference between ELF-MF values during trip and rail switch $(\mathrm{P}<0.001)$ and at the time of trip and deceleration situations $(\mathrm{P}<0.001)$. The SMF values showed a significant difference between all the measurement situations, except for between acceleration and in-trip. In DC trains, the SMF values were statistically different between situations of acceleration and rail switch $(\mathrm{P}=$ 0.021), in-trip and deceleration $(\mathrm{P}=0.028)$, and in-trip and rail switch $(\mathrm{P}=0.008)$.

Table 3 provides a comparison between the maximum SMF and ELF-MF values in various types of trains while acceleration, motion, deceleration, and rail switch (Table 3 ).

Comparing AC and DC trains, a significant difference was found only in rail switch situation $(\mathrm{p}=0.006)$. ELF-MF values in AC and ACi trains showed a significant difference in all the measurement situations. It was also significantly different between DC and ACi trains in acceleration $(\mathrm{P}<$ 0.001) and in-trip $(\mathrm{P}<0.001)$ situations.

Although the p-value was 0.06, the SMF showed no significant difference between AC and DC trains in different measurement situations.

The SMF values of AC and DC trains showed no significant difference in all the measurement situations, except for in deceleration and rail switch $(P=0.06)$.

Table 4 compares maximum SMF and ELF-MF values between different types of the trains. The comparison is just based on maximum MF values regardless of different measurement situations.

The ELF-MF values were statistically different between $\mathrm{ACi}$ and $\mathrm{AC}$ trains $(\mathrm{P}<0.001)$ as well as between ACi and DC trains $(\mathrm{P}<0.001)$.

\section{Discussion}

The present study compares the intensity of ELF-MF and SMF of in-city and intercity trains at different situations. The measurement results reveal drivers' exposure to ELF-MF and SMF at the workplace. According to the results, maximum SMF was $0.52 \mathrm{mT}$ measured at DC trains. This can be attributed to the type of engine in DC trains, because the engine of this type of trains directly uses 750 VDC for traction. Furthermore, maximum ELF-MF was 7.90 $\mu \mathrm{T}$ reported from ACi trains. This may be due to the type of engine, type of locomotive power (overhead power lines instead of third rail), and the speed difference between the two types of in-city and intercity trains that leads to the difference in energy consumption (12). It is noteworthy that there was no possibility to measure the magnetic fields near the engine because the engine of intercity trains was in a closed chamber in the rear of the locomotive. Therefore, all the measurements were done at the driver's cabin. For this reason, the measured SMF at these trains was $<0.1$ $\mathrm{mT}$. It seems that the drivers' exposure is $<0.1 \mathrm{mT}$ as the lowest measurable amount of HI-3550 device. However, the 
Table 1. The Intensity of ELF-MF $(\mu \mathrm{T})$ and SMF $(\mathrm{mT})$ in Different Trains and Situations

\begin{tabular}{|c|c|c|c|c|c|c|c|c|c|c|c|c|c|c|}
\hline & & \multicolumn{3}{|c|}{ Acceleration } & \multicolumn{3}{|c|}{ In trip } & \multicolumn{3}{|c|}{ Deceleration } & \multicolumn{3}{|c|}{ Switching } & \multirow[t]{2}{*}{ Total mean (SD) } \\
\hline & & Min & Max & Mean(SD) & Min & Max & Mean (SD) & Min & Max & Mean (SD) & Min & Max & Mean (SD) & \\
\hline \multirow[t]{2}{*}{ AC } & ELF-MF $(n=132)$ & 0.08 & 1.37 & $0.43(0.3)$ & 0.18 & 5.24 & $0.66(0.91)$ & 0.16 & 1.30 & $0.47(0.31)$ & 0.14 & 0.33 & $0.20(0.05)$ & $0.42(0.53)$ \\
\hline & $\operatorname{SMF}(n=132)$ & $<0.1$ & 0.35 & $0.14(0.06)$ & $<0.1$ & 0.33 & $0.12(0.07)$ & $<0.1$ & 0.17 & $0.08(0.05)$ & $<0.1$ & $<0.1$ & $<0.1(<0.1)$ & $0.08(0.075)$ \\
\hline \multirow[t]{2}{*}{ DC } & $\operatorname{ELF}-\mathrm{MF}(\mathrm{n}=88)$ & 0.11 & 1.87 & $0.46(0.33)$ & 0.12 & 0.83 & $0.27(0.13)$ & 0.20 & 0.93 & $0.38(018)$ & 0.19 & 0.37 & $0.27(0.04)$ & $0.34(0.22)$ \\
\hline & $\operatorname{SMF}(n=88)$ & $<0.1$ & 0.30 & $0.12(0.06)$ & $<0.1$ & 0.52 & $0.11(0.10)$ & $<0.1$ & 0.26 & $0.04(0.07)$ & $<0.1$ & 0.12 & $0.02(0.05)$ & $0.07(0.086)$ \\
\hline $\mathrm{AC}_{\mathrm{i}}$ & $\operatorname{ELF}-\mathrm{MF}(\mathrm{n}=88)$ & 0.63 & 5.17 & $2.10(1.31)$ & 0.33 & 7.90 & $2.53(2.23)$ & 0.12 & 1.53 & $0.47(0.34)$ & 0.16 & 1.53 & $0.38(0.31)$ & $1.36(1.67)$ \\
\hline
\end{tabular}

Abbreviation: $n$, Number of repeated measurements of SMF and ELF-MF.

maximum exposure to ELF-MF was measured among the drivers of these trains. The results also showed that in none of the trains or states, drivers' exposure exceeded the recommended limits. In a research by Contessa et al. in Italy, $\mathrm{AC}$ and DC trains were compared in terms of the level of electromagnetic fields. They found that at a height of $1 \mathrm{~m}$ from the floor of the driver's cabin, the maximum ELF-MF and SMF values were $9.31 \mu \mathrm{T}$ and $0.12 \mathrm{mT}$ in AC trains and $4 \mu \mathrm{T}$ and $0.16 \mathrm{mT}$ in DC trains, respectively (15). Study of Halgamuge et al. reported that maximum values of ELFMF in AC trains at rear floor, middle floor, front floor, driver side seat, and above the train drivers' cabin were 3.60, 8.70, $8.30,4.70$, and $5.50 \mathrm{mG}$, respectively (4). In addition, the research of Ptitsyna et al. reported maximum ELF-MF of 44 $\mu \mathrm{T}$ in AC locomotives. In addition, they reported SMF of 0.4 $\mathrm{mT}$ in DC-powered transport systems (14). These results are in line with the findings of the current study presented in Table 1. According to other study findings, the measured ELF-MF and SMF in different types of trains did not exceed the ACGIH-TLV.This was also confirmed by the results of the present study.

In the current research, maximum values of ELF-MF and SMF were reported from AC and DC trains, respectively. This is in line with the findings of Nakagava and Koana (1993) indicating that maximum ELF-MF and S MF in AC trains were respectively $0.2-150 \mu \mathrm{T}$ and $0.1-4 \mathrm{mT}$, and in DC trains were $0.5-5 \mu \mathrm{T}$ and $0.05-0.2 \mathrm{mT}$ (18). Their results showed that ELF-MF in AC trains was higher than that of DC trains. Nevertheless, DC trains did not show higher rates of SMF compared to AC trains. Although in their study, the ELF-MF and SMF values were higher than those of the present research were, the amounts still did not exceed the recommended occupational limits. Moreover, Ptitsyna et al. found that SMF is the major portion of the MF encountered on board Russian DC powered transport systems rather than AC locomotives (14). However, the SMF values in Ptitsyna et al. and Nakagava and Koanas' research and other relevant studies were ten times the amount of the background level (30 to $60 \mu \mathrm{T}(19)$ ). In a study conducted on intercity trains in London, the aver- age SMF was measured as $200 \mu \mathrm{T}$ in the driver's cabin, 16 - $64 \mu \mathrm{T}$ in passengers' wagon, and $1 \mathrm{mT}$ at the height of the seat and on the floor (1). They revealed that when the measurement height changed, the SMF also raised significantly so that the SMF on the floor was several times higher than the SMF at the seat height. This change can be attributed to the rapid changes in magnetic fields along the trains. In a study on AC trains by Ptitsyna et al. it was reported that the magnetic flux density in acceleration mode is higher than that of deceleration and zero-current status $(16.7 \mathrm{~Hz})$. They also showed that the magnetic flux density changes in situations of switching, acceleration, and braking. This change is progressive in acceleration mode and descending at the time of braking (2). Another study measured maximum SMF of DC train when passing substations (in the trips) (14). Moreover, Halgamuge et al. reported that magnetic field strength varies with the speed of trains (4). The results in Table 2 confirm these ascending and descending changes while acceleration and breaking in AC and ACi trains. As Table 2 suggests, magnetic flux density at the times of acceleration and breaking showed a significant difference in $\mathrm{AC}(\mathrm{P}<0.001)$ and $\mathrm{ACi}$ trains $(\mathrm{P}<0.002)$. In the same study as well as in the research by Farag et al. (2003) (10), it was revealed that the magnetic flux density also increases with increasing speed. The speed difference is also observed in in-city and intercity trains of Tehran City. Intercity trains, due to their higher speed, use more energy and in consequence had greater ELF-MF compared to incity trains. Since the lowest measurable value by HI-3550 magnetic field monitor is $0.1 \mathrm{mT}$, in some spots with lower magnetic fields, the measured values were recorded as < 0.1.

As the obtained results suggest, in none of the situations, the exposure of train drivers to ELF-MF and SMF exceeded the threshold limits recommended by ACGIH. However, the effects of these fields should not be ignored because different studies have reported adverse health consequences due to these fields, such as leukemia and Hodgkin $(20,21)$. Therefore, it is required to limit and reduce exposure as much as possible. 
Table 2. A comparison on ELF-MF and SMF Values in AC, DC, and ACi Trains

\begin{tabular}{|c|c|c|c|c|c|c|}
\hline \multirow[t]{2}{*}{ MF Type } & \multirow[t]{2}{*}{ Trains Type } & \multicolumn{2}{|c|}{ Measurement Situation } & \multirow[t]{2}{*}{$\operatorname{MD}(\mathbf{I}-\mathbf{J})$} & \multirow[t]{2}{*}{ SE } & \multirow[t]{2}{*}{ PValue } \\
\hline & & (I) & (J) & & & \\
\hline \multirow{17}{*}{ ELF } & \multirow{5}{*}{$\mathrm{AC}$} & \multirow{3}{*}{ Acceleration } & In trip & -0.27 & 0.15 & 0.32 \\
\hline & & & Deceleration & -0.10 & 0.15 & 0.90 \\
\hline & & & Switching & 0.34 & 0.17 & 0.20 \\
\hline & & In trip & Switching & 0.61 & 0.17 & $0.004^{\mathrm{a}}$ \\
\hline & & Deceleration & Switching & 0.45 & 0.17 & $0.05^{\mathrm{a}}$ \\
\hline & \multirow{6}{*}{ DC } & \multirow{3}{*}{ Acceleration } & In trip & 0.25 & 0.10 & 0.06 \\
\hline & & & Deceleration & 0.09 & 0.10 & 0.75 \\
\hline & & & Switching & 0.28 & 0.11 & 0.06 \\
\hline & & \multirow{2}{*}{ In trip } & Deceleration & -0.15 & 0.10 & 0.42 \\
\hline & & & Switching & 0.033 & 0.11 & 0.99 \\
\hline & & Deceleration & Switching & 0.18 & 0.11 & 0.35 \\
\hline & \multirow{6}{*}{$\mathrm{AC}_{\mathrm{i}}$} & \multirow{3}{*}{ Acceleration } & In trip & -0.45 & 0.5 & 0.84 \\
\hline & & & Deceleration & 2.07 & 0.5 & $0.002^{\mathrm{a}}$ \\
\hline & & & Switching & 2.21 & 0.6 & $0.003^{\mathrm{a}}$ \\
\hline & & \multirow{2}{*}{ In trip } & Deceleration & 2.53 & 0.55 & $<0.001^{\mathrm{a}}$ \\
\hline & & & Switching & 2.66 & 0.61 & $<0.001^{\mathrm{a}}$ \\
\hline & & Deceleration & Switching & 0.13 & 0.61 & 0.99 \\
\hline \multirow{11}{*}{ Static } & \multirow{5}{*}{$\mathrm{AC}$} & \multirow[b]{2}{*}{ Acceleration } & In trip & 0.01 & 0.01 & 0.75 \\
\hline & & & Deceleration & 0.06 & 0.01 & $<0.001^{\mathrm{a}}$ \\
\hline & & \multirow{2}{*}{ In trip } & Deceleration & -0.05 & 0.01 & $0.009^{\mathrm{a}}$ \\
\hline & & & Switching & 0.16 & 0.01 & $<0.001^{\mathrm{a}}$ \\
\hline & & Deceleration & Switching & 0.11 & 0.01 & $<0.001^{\mathrm{a}}$ \\
\hline & \multirow{6}{*}{ DC } & \multirow{3}{*}{ Acceleration } & In trip & -0.01 & 0.03 & 0.98 \\
\hline & & & Deceleration & 0.08 & 0.03 & 0.07 \\
\hline & & & Switching & 0.11 & 0.04 & $0.021^{\mathrm{a}}$ \\
\hline & & \multirow{2}{*}{ In trip } & Deceleration & 0.10 & 0.03 & $0.028^{\mathrm{a}}$ \\
\hline & & & Switching & 0.13 & 0.04 & $0.008^{\mathrm{a}}$ \\
\hline & & Deceleration & Switching & 0.03 & 0.04 & 0.87 \\
\hline
\end{tabular}

Abbreviation: MD, mean difference; SE, Std. error.

${ }^{\text {a }}$ Significant at $<0.05$.

\section{Acknowledgments}

This article is based on a research project (grant No. 9104-132-20439) sponsored by Tehran University of Medical Sciences. The authors thank the drivers, experts of HSE department, and all personnel of Tehran urban and suburban subway operation company who involved in this project. It should be noted that the content presented in the article is the authors' opinion and does not reflect the opinion of the company.

\section{Footnote}

Conflict of Interest: The authors declare that they have no conflicting interests. 
Jalilian Het al.

Table 3. A Comparison on ELF-MF and SMF Values in Various Types of Trains in Different Situations

\begin{tabular}{|c|c|c|c|c|c|c|c|c|c|c|c|c|c|}
\hline \multirow[t]{3}{*}{ MF type } & \multirow[t]{3}{*}{ Trains type } & \multicolumn{12}{|c|}{ Measurement Situation } \\
\hline & & \multicolumn{3}{|c|}{ Acceleration } & \multicolumn{3}{|c|}{ In trip } & \multicolumn{3}{|c|}{ Deceleration } & \multicolumn{3}{|c|}{ Switching } \\
\hline & & $\operatorname{MD}(\mathbf{I}-\mathrm{J})$ & SE & PValue & $\operatorname{MD}(\mathbf{I}-\mathrm{J})$ & SE & PValue & $\operatorname{MD}(I-J)$ & SE & PValue & $\operatorname{MD}(\mathbf{I}-\mathrm{J})$ & SE & PValue \\
\hline \multirow{6}{*}{ ELF } & $\mathrm{AC}(\mathrm{I})$ & -0.02 & 0.30 & 0.99 & 0.500 & 0.46 & 0.52 & 0.18 & 0.11 & 0.23 & -0.08 & 0.02 & $0.006^{*}$ \\
\hline & $\mathrm{DC}(\mathrm{J})$ & & & & & & & & & & & & \\
\hline & $\mathrm{AC}(\mathrm{I})$ & -1.98 & 0.30 & $<0.001^{*}$ & -2.16 & 0.46 & $<0.001^{*}$ & 0.20 & 0.11 & 0.17 & -0.11 & 0.02 & $<0.001^{*}$ \\
\hline & $\mathrm{AC}_{\mathrm{i}}(\mathrm{J})$ & & & & & & & & & & & & \\
\hline & $\mathrm{DC}(\mathrm{I})$ & -1.96 & 0.33 & $<0.001^{*}$ & -2.66 & 0.50 & $<0.001^{*}$ & 0.01 & 0.12 & 0.98 & -0.03 & 0.02 & 0.46 \\
\hline & $\mathrm{AC}_{\mathrm{i}}(\mathrm{J})$ & & & & & & & & & & & & \\
\hline & & $t$ & \multicolumn{2}{|c|}{ P Value } & t & \multicolumn{2}{|c|}{ PValue } & $\mathrm{t}$ & \multicolumn{2}{|c|}{ PValue } & t & \multicolumn{2}{|c|}{ PValue } \\
\hline \multirow{2}{*}{ Static } & $\mathrm{AC}$ & \multirow{2}{*}{0.94} & \multirow{2}{*}{0.35} & \multirow{2}{*}{-0.30} & \multirow{2}{*}{0.76} & \multirow{2}{*}{1.89} & \multirow{2}{*}{0.06} & \multirow{2}{*}{-1.99} & \multirow{2}{*}{0.06} & & & & \\
\hline & $\mathrm{DC}$ & & & & & & & & & & & & \\
\hline
\end{tabular}

Table 4. Comparison of Maximum SMF and ELF-MF Between Different Types of Trains

\begin{tabular}{|c|c|c|c|c|c|}
\hline \multirow[t]{2}{*}{ MF Type } & \multicolumn{2}{|c|}{ Trains Type } & \multirow[t]{2}{*}{$\mathbf{M D}(\mathbf{I}-\mathbf{J})$} & \multirow[t]{2}{*}{ SE } & \multirow[t]{2}{*}{ PValue } \\
\hline & (I) & (J) & & & \\
\hline \multirow{3}{*}{ ELF } & \multirow{2}{*}{ AC } & DC & 0.16 & 0.17 & 0.62 \\
\hline & & $\mathrm{ACi}$ & -1.09 & 0.1 & $<0.001^{*}$ \\
\hline & DC & $\mathrm{ACi}$ & -1.26 & 0.19 & $<0.001^{*}$ \\
\hline Static & AC & DC & 0.005 & 0.01 & 0.89 \\
\hline
\end{tabular}

\section{References}

1. Chadwick P, Lowes F. Magnetic fields on British trains. Ann Occup Hyg. 1998;42(5):331-5. [PubMed: 9729921].

2. Ptitsyna N, Ponzetto A, editors. Magnetic fields encountered in electric transport: Rail systems, trolleybus and cars. Electromagnetic Compatibility (EMC EUROPE), 2012 International Symposium on. 2012; IEEE; pp. 1-5.

3. Tell RA, Sias G, Smith J, Sahl J, Kavet R. ELF magnetic fields in electric and gasoline-powered vehicles. Bioelectromagnetics. 2013;34(2):15661. doi: 10.1002/bem.21730. [PubMed: 22532300].

4. Halgamuge MN, Abeyrathne CD, Mendis P. Measurement and analysis of electromagnetic fields from trams, trains and hybrid cars. Radiat Prot Dosimetry. 2010;141(3):255-68. doi: 10.1093/rpd/ncq168. [PubMed: 20554578].

5. Neutra RR. Glossary of terms used when discussing exposure to electric and magnetic fields. J Epidemiol Commun Health. 2005;59(7):54650. doi: 10.1136/jech.2003.019075.

6. American Conference of Governmental Industrial Hygienists (ACGIH) . TLVs and BEIs. Kemper meadow drive. ; 2012. pp. 124-6.

7. Floderus B, Tornqvist S, Stenlund C. Incidence of selected cancers in Swedish railway workers, 1961-79. CancerCauses Control. 1994;5(2):18994. [PubMed: 8167266].

8. Alfredsson L, Hammar N, Karlehagen S. Cancer incidence among male railway engine-drivers and conductors in Sweden, 1976-90. Cancer Causes Control. 1996;7(3):377-81. [PubMed: 8734832].

9. Pfluger DH, Minder CE. Effects of exposure to $16.7 \mathrm{~Hz}$ magnetic fields on urinary 6-hydroxymelatonin sulfate excretion of Swiss railway workers. J Pineal Res. 1996;21(2):91-100. [PubMed: 8912234].

10. Santangelo L, Di Grazia M, Liotti F, De Maria E, Calabro R, Sannolo $\mathrm{N}$. Magnetic field exposure and arrythmic risk: evaluation in railway drivers. Int Arch Occup Environ Health. 2005;78(4):337-41. doi: 10.1007/s00420-004-0541-2. [PubMed: 15750820].
11. Roosli M, Egger M, Pfluger D, Minder C. Cardiovascular mortality and exposure to extremely low frequency magnetic fields: a cohort study of Swiss railway workers. Environ Health. 2008;7:35. doi: 10.1186/1476069X-7-35. [PubMed: 18593477].

12. Farag A, Hussain H, Said I, Kader MA, Rahman NA. Electromagnetic Fields associated with transportation systems in Malaysia. Proceedings of the International Conference on Non-Ionizing Radiation at UNITEN (ICNIR 2003). 2003. pp. 1-15.

13. Ptitsyna N. Electric Vehicle Magnetic Fields and Their Biological Relevance. J Sci Res Rep. 2014;3(13):1753-70. doi: 10.9734/jsrr/2014/9736.

14. Ptitsyna NG, Kopytenko YA, Villoresi G, Pfluger DH, Ismaguilov V, Iucci $\mathrm{N}$, et al. Waveform magnetic field survey in Russian DC and Swiss AC powered trains: a basis for biologically relevant exposure assessment. Bioelectromagnetics. 2003;24(8):546-56.doi:10.1002/bem.10135. [PubMed: 14603474].

15. Contessa GM, Falsaperla R, Brugaletta V, Rossi P. Exposure to magnetic fields of railway engine drivers: a case study in Italy. Radiat Prot Dosimetry. 2010;142(2-4):160-7. doi: 10.1093/rpd/ncq270.[PubMed: 21071462].

16. Dietrich FM, Jacobs WL. Survey and assessment of electric and magnetic field (EMF) public exposure in the transportation environment. Cambridge, MA (United States): Electric Research and Management, Inc., State College, PA (United States); John A. Volpe National Transportation Systems Center; 1999.

17. European Committee for Electrotechnical Standardization (CENELEC) . Measurement procedures of magnetic field levels generated by electronic and electrical apparatus in the railway environment with respect to human exposure (standard no. EN 50500: 2008). Brussels, Belgium: CENELEC; 2008.

18. Nakagava M, Koana T. Electricity and magnetism in biology and medicine. San Francisco: Press Inc; 1993.

19. IARC Working Group on the Evaluation of Carcinogenic Risks to Humans . Non-ionizing Radiation: Static and extremely low-frequency 
(ELF) electric and magnetic fields. World Health Organization; 2002. 20. Roosli M, Lortscher M, Egger M, Pfluger D, Schreier N, Lortscher E, et al Leukaemia, brain tumours and exposure to extremely low frequency magnetic fields: cohort study of Swiss railway employees. Occup Environ Med. 2007;64(8):553-9. doi: 10.1136/oem.2006.030270. [PubMed:
17525094].

21. Savitz DA. Invited commentary: electromagnetic fields and cancer in railway workers. Am JEpidemiol. 2001;153(9):836-8. [PubMed: 11323312] discussion 839-40. 